Résumés des conférences et travaux

\title{
Histoire de l'art de la Renaissance
}

\section{Sabine Frommel}

\section{OpenEdition \\ Journals}

\section{Édition électronique}

URL : https://journals.openedition.org/ashp/724

DOI : 10.4000/ashp.724

ISSN : 1969-6310

\section{Éditeur}

Publications de l'École Pratique des Hautes Études

\section{Édition imprimée}

Date de publication : 1 octobre 2009

Pagination : 248-249

ISSN : 0766-0677

\section{Référence électronique}

Sabine Frommel, "Histoire de l'art de la Renaissance ", Annuaire de l'École pratique des hautes études (EPHE), Section des sciences historiques et philologiques [En ligne], 140 | 2009, mis en ligne le 19 octobre 2009, consulté le 06 juillet 2021. URL : http://journals.openedition.org/ashp/724 ; DOI : https://doi.org/ 10.4000/ashp.724 


\title{
HISTOIRE DE L'ART DE LA RENAISSANCE
}

\author{
Directeur d'étude : $\mathrm{M}^{\mathrm{me}}$ Sabine Frommel
}

Programme de l'année 2007-2008 : Architecture dans la peinture : l'architecture imaginée et son rôle dans l'évolution des typologies et des formes.

Les conférences de cette année ont prolongé des réflexions de l'année universitaire précédente, centrées sur la représentation de l'architecture dans la peinture et dans le dessin. Il s'est agi plus particulièrement de savoir jusqu'à quel point l'architecture imaginée a contribué à l'évolution des langages de l'art de bâtir et dans quelle mesure ce phénomène a pu conduire à une vision plus précise de la genèse de ce vocabulaire. $\mathrm{Du} \mathrm{XV} \mathrm{V}^{\mathrm{e}}$ au XVII ${ }^{\mathrm{e}}$ siècle, édifices, ruines et fragments d'architecture se multiplient sur les toiles et les cartons, créant un cadre monumental au sein duquel se meuvent des figures. Parfois un peintre-architecte réussit à lancer de nouveaux modèles, même si dans la grande majorité des cas il ne fait qu'emprunter des motifs à l'art de bâtir. Grâce à ses capacités coordinatrices, l'architecture assigne une place précise aux figures, en instaurant un rapport entre celles-ci et l'espace. Dès le milieu du $\mathrm{Xv}^{\mathrm{e}}$ siècle, la représentation de la ville fait l'objet de recherches censées mettre à l'épreuve des concepts théoriques et reflèter la perception de l'artiste et de la communauté à laquelle il appartient. Dans le même temps, les monuments imaginés gagnent une charge métaphorique rendant visible des traditions, des institutions, des idéologies et même des états d'âme. Après une phase d'expérimentation prodigieuse sous la tutelle de Bramante et de son école, un processus de codification du répertoire prend forme à partir des années trente $\mathrm{du} \mathrm{XVI}^{\mathrm{e}}$ siècle qui, à la faveur de la diffusion des traités d'architecture, engendre une avalanche de variations à travers toute l'Europe. Si pendant la deuxième moitié du Cinquecento l'élan créateur a tendance à s'essoufler, certains artistes notamment dans les états septentrionaux de la péninsule, notamment Titien et Tintoret, continuent à innover et à élargir l'horizon des paradigmes.

Au XVII ${ }^{e}$ siècle s'intensifie le dialogue entre Nord et Sud qui avait initié un épanouissement au siècle précédent, surtout entre l'Italie et la France. Peintre à la fois romain et français, maillon entre la tradition du Cinquecento et le XVII siècle, Nicolas Poussin restitue les monuments de l'Antiquité avec un zèle philologique et archéologique qui accomplit les préoccupations des maîtres du Primo Cinquecento. Le temple étrusque de la Peste d'Ashod - que seul une lecture du traité de Vitruve a rendu possible - est un exemple pertinent de cette tendance. Parallèlement, le parcours artistique de Poussin doit aussi beaucoup aux courants français. Cinq des sept tableaux de la première série des Sacraments (seconde moitié des années trente) trahissent son intérêt croissant pour une conception géométrique de l'espace, la symétrie et des effets prononcés de lumière et de couleur. Les paysages avec Saint Jean à Patmos et Saint Mathieu et l'ange révèlent nettement l'influence des méthodes perspectives de Girard Desargues, mathématicien et géomètre, qui semblent avoir conduit l'artiste vers un classicisme de plus en plus intransigeant. La démarche et les techniques de Desargues ont bénéficié 
d'une ample diffusion grâce aux ouvrages d'Abraham Bosse dont les échos se firent nettement sentir dans la peinture, l'architecture et même l'art des jardins.

En instaurant une nouvelle vision de la nature, Claude Lorrain accorde également un rôle primordial à l'architecture, mais ses monuments imaginaires appartiennent à un répertoire plutôt stéréotypé, soumis à une attitude de plus en plus académique. Ses scénographies architecturales peuplées de personnages minuscules reflètent un autre lien avec le pouvoir suprême. À côté du classiscisme intransigeant de Poussin, les monuments imaginaires de Pietro da Cortona apparaissent comme des coulisses de théâtre; il suffit de comparer le traitement foncièrement différent de L'enlèvement des Sabines de Poussin et de Cortone où le premier surprend par l'attention à la restitution de chaque architectural, tandis que le second se distingue par la touche rapide d'une grande puissance suggestive.

L'autorité des modèles du Primo Cinquecento s'exerce encore à travers les œuvres de Domenichino qui, à la différence de son maître Annibale Carraci, adhère à un vocabulaire qui renoue avec Raphaël. La grande fresque avec La construction de l'Abbaye du monastère de Saint-Nil à Grottaferrata montre une virtuosité dans la représentation d'un chantier de construction. De même dans ses réalisations dans la ville éternelle, comme à Saint-Louis-des-Français (cappella di Santa Cecilia), il reste fidèle aux vocabulaire architectural lêgué par le Primo Cinquecento, assurant ainsi une continuité entre Cinque et Seicento.

Dans la seconde moitié du siècle, les fresques des voûtes et des coupoles posent un nouveau défi pour les peintres-architectes, en quête d'effets hardis de trompe-l'œil. Afin d'établir une construction perspective rigoureusement coordonnée, Andrea Pozzo renoue avec les théories d'Abraham Bosse. À Saint-Ignace à Rome, les limites entre l'architecture construite et celle peinte se dissolvent en un illusionisme qui transfigure les limites réelles de l'espace. Nous nous sommes demandé jusqu'à quel point ces compositions monumentales poursuivent les recherches des peintres-architectes de la Renaissance. Depuis la camera picta d'Andrea Mantegna à la chute des géants de Giulio Romano, en passant par la voûte de la chapelle Sixtine, le Cinquecento offre des paradigmes fondamentaux pour la mise au point de fresques monumentales, élaborés sur la base d'un système architectural. Le dialogue entre l'architecture imagiaire et la figure humaine, le traitement de celle-ci, la couleur et les techniques trahissent toutefois des mutations essentielles. Le poids de l'héritage du Cinquecento continue à se faire sentir au XVIII ${ }^{\mathrm{e}}$ siècle à travers l'opus de Giambattista Tiepolo qui s'inspire de la tradition vénitienne et notamment de Véronèse.

$\mathrm{Au}$ cours de la seconde moitié du XVIII ${ }^{\mathrm{e}}$ siècle l'architecture projetée et l'architecture imaginée évoluent selon le même rythme. Le retour à l'Antiquité et sa résurrection pendant la Renaissance président au vocabulaire. Dans les œuvres de Jean-Louis David, le Sermont des Horaces par exemple, les formes austères d'un portique toscan/dorique sont censées évoquer les vertus républicaines, la vigueur spartiate et les sentiments patriotiques. La tradition du Cinquecento et du Seicento, les paradigmes architecturaux de Raphaël, de Michel-Ange, de Poussin ou de maîtres bolonais comme Domenichino constituent une référence principale pour le peintre français.

La parallèle entre l'évolution des formes projetées et imaginées, mais aussi les écarts entre elles, apportent un éclairage inédit sur les mutations des langages architecturaux et rendent nécessaires une confrontation systématique des deux paramètres. 